\title{
QUEM SÃO OS ESTUDANTES DA \\ CARREIRA DO MAGISTÉRIO?
}

Paulo César Geglio (UFPB)*

\begin{abstract}
RESUMO
Este trabalho apresenta uma análise e discussão a respeito do perfil social e econômico de estudantes concluintes dos cursos de licenciaturas das instituições de ensino superior brasileiras. Os dados foram coletados dos relatórios do Exame Nacional de Desempenho de Estudantes (Enade), referentes aos anos de 2005, 2008, 2011 e 2014. Trata-se de uma análise comparativa das informações de cada edição do exame no que diz respeito às características socioeconômicas dos estudantes (idade, sexo, cor, renda familiar mensal, sustentação financeira, estado civil e atividade laboral). As informações foram capturadas nos relatórios-síntese, disponíveis no site do Inep. Concluímos que houve expressivo aumento na quantidade de estudantes desses cursos, um público majoritariamente feminino, trabalhador, com idade avançada em relação à faixa de 18 a 24 anos e com baixa renda familiar.

Palavras-chave: Avaliação da educação superior. Acesso ao ensino. Estudante. Curso de formação de professores.
\end{abstract}

\begin{abstract}
WHO ARE THE STUDENTS OF THE TEACHING CAREER?

This paper presents an analysis and discussion about the undergraduating students' social and economic profile of licentiate courses at Brazilian higher education institutions. The data were collected from the Enade reports with reference to 2005, 2008, 2011 and 2014. This is a comparative examination with information of each exam edition with regard to age, sex, color / ethnicity, monthly family income, financial support, marital status, and work activity. The information was retrieved from the synthesis reports, available on the Inep website. We concluded that there was a significant increase in the number of students in these courses, a larger female audience, hardworking, older students regarding the 18 to 24 age group and with low family income.
\end{abstract}

Keywords: Higher education assessment. Access to education. Student. Teacher training course.

\section{RESUMEN}

\section{¿QUIÉNES SON LOS ESTUDIANTES DE LA CARRERA DE MAGISTERIO?}

Este estudio presenta un análisis y una discusión acerca del perfil social y económico de estudiantes concluyentes de los cursos de licenciaturas de las instituciones de

\footnotetext{
Doutor em Educação pela Pontifícia Universidade Católica de São Paulo (PUC/SP). Professor Associado no Departamento de Fundamentação da Educação da Universidade Federal da Paraíba (UFPB). Membro do grupo de pesquisa sobre formação docente do Centro de Educação da UFPB. E-mail: pgeglio@yahoo.com.br
} 
enseñanza superior brasileñas. Los datos fueron recolectados de los informes del Examen Nacional de Desempeño de Estudiantes (Enade), referentes a los años de 2005, 2008, 2011 y 2014. Se trata de un análisis comparativo de las informaciones de cada edición del examen en lo que respecta a las características socioeconómicas de los estudiantes (edad, sexo, color, ingreso familiar mensual, sostenimiento financiero, estado civil y actividad laboral). Las informaciones fueron recogidas en los informessíntesis, disponibles en el sitio web del Inep. Concluimos que hubo un expresivo aumento en la cantidad de estudiantes de esos cursos, un público mayoritariamente femenino, trabajador, con edad avanzada en relación con el grupo del 18 a 24 años y con bajos ingresos familiares.

Palabras-clave: Evaluación de la educación superior. Acceso a la educación. Estudiante. Curso de formación de profesores.

\section{Introdução}

Uma das contribuições das avaliações educacionais em larga escala - além da principal, que é gerar dados específicos sobre o desempenho de estudantes - é coletar informações socioeconômicas dos participantes, como faz, por exemplo, o Exame Nacional de Desempenho de Estudantes (Enade). Trata-se de um compilado de microdados de significativa importância para estudos que tentam compreender se há correlação entre o fenômeno da escolarização, e da aprendizagem em particular, com o perfil social, econômico, histórico e familiar dos indivíduos. Importante destacar que a, Lei no 9.394 (BRASIL, 1996), que estabelece as diretrizes e bases da educação nacional, prevê que o governo tem a incumbência de coletar, analisar e socializar informações sobre a educação, o que corrobora a consecução desse tipo de avaliação.

As avaliações em larga escala, também conhecidas como avaliações externas, realizadas por órgãos governamentais, são recentes no Brasil. A primeira experiência ocorreu por meio do Exame Nacional de Curso (ENC), conhecido como "Provão", que foi instituído com a Lei nº 9.131 (BRASIL, 1995), que alterou dispositivos da Lei 4.024 e instituiu avaliações periódicas dos cursos de ensino superior. Foi um sistema de avaliação que gerou muita polêmica no meio acadêmico e sofreu boicotes tanto de instituições de ensino superior, como de universitários, por ser considerada uma ação desarticulada de outros instrumentos avaliativos e por se configurar muito mais como instrumento de controle governamental e forma de promover o ranking das instituições de ensino superior.

Em substituição ao ENC foi instituído pelo governo federal, no ano de 2004, o Enade, como integrante do Sistema Nacional de Avaliação da Educação Superior (Sinaes). Este último surgiu com a pretensão de se constituir em um conjunto articulado de mecanismos e parâmetros avaliativos da educação superior, considerando a tríplice função social da universidade, que é promover o ensino, a pesquisa e a extensão, além de orientar a expansão da sua oferta e o contínuo aumento da eficácia das instituições e sua efetividade acadêmica e social (BRASIL, 2004).

O Enade é realizado anualmente para uma quantidade alternada de cursos, de modo que cada um deles passa pelo procedimento trienalmente. Além da prova feita presencialmente, também é realizada, antecipadamente e de forma virtual, uma coleta de dados sobre o perfil social, econômico e escolar dos participantes, assim como sobre a percepção deles em relação aos aspectos acadêmicos e estruturais do curso. No dia do exame eles respondem um questionário sobre a prova. Esse conjunto de dados é valioso para entender a maneira como ocorre a educação superior no Brasil.

Considerando o fato de ser recente esse tipo de avaliação no bojo das políticas educacionais, as análises e pesquisas em torno dela e seus dados ainda estão se constituindo. Não obstante, já existem importantes trabalhos, muitos deles compilados ou realizados pelos integrantes do Grupo Estratégico de Análise da Educação Superior (GEA-ES), a 
exemplo das produções de Ristoff (2013, 2016), que apresentam discussões sobre o perfil socioeconômico e étnico dos estudantes com a democratização do acesso à educação superior. Há também outros autores que oferecem contribuições para a discussão, a partir de dados do Enade, sobretudo com o uso das informações coletadas por meio do questionário aplicado aos estudantes (GRIBOSKI, 2012; SILVA; VENDRAMINI; LOPES, 2010; WAINER; MELGUIZO, 2017). Algumas das produções focam especificamente na carreira do magistério (BRITO, 2007; BRITTO; WALTENBERG, 2014; GATTI, 2010; LOUZANO et al, 2010), como é o nosso caso no presente texto.

Nossa contribuição neste trabalho, assim como os citados, se concentra na análise do perfil dos estudantes das licenciaturas, com base nas informações coletadas pelo Inep por ocasião do Enade. Conquanto, diferentemente dos demais, apresentamos uma análise situada no percurso histórico das edições do exame, com a perspectiva de perceber o comportamento dos dados relativos à dinâmica evolutiva dos indivíduos e das transformações sociais no decorrer de uma década, mormente ao que se refere à expansão das vagas na educação superior.

\section{Percurso metodológico}

Para a realização deste trabalho, utilizamos os dados presentes nos relatórios síntese de área do Enade que estão disponíveis no site do Instituto Nacional de Estudos e Pesquisas Educacionais Anísio Teixeira (Inep). Os documentos contêm informações quantitativas e comentários sobre o desempenho dos estudantes na realização do exame, bem como a visão deles sobre sua performance na resolução das questões, além de dados sobre suas características sociais, econômicas, profissionais, familiares e acadêmicas. Nos concentramos especificamente nas informações referentes à idade, sexo, cor, renda familiar mensal, sustentação financeira, estado civil e atividade laboral. Estas informações estão presentes em todos relatórios e, portanto, nos permite fazer um exame comparativo da maioria desses dados em relação à evolução de quase uma década. Os cursos de licenciatura que elegemos para análise são aqueles presentes em todos os rela- tórios: Biologia, Educação Física, Filosofia, Física, Geografia, História, Letras, Matemática, Pedagogia e Química. No caso do curso de Educação Física, os anos de aplicação do exame foram 2004, 2007, 2011 e 2014; como o referido curso está classificado também na área de saúde, seu exame foi realizado no conjunto dos cursos dessa área do conhecimento, mas em 2011 e 2014 ele foi aplicado somente para a licenciatura, juntamente com os demais. Outro aspecto a ser considerado é que nos anos de 2005 e 2008 os estudantes ingressantes e concluintes dos cursos foram selecionados para realizar o exame, pois a intenção era observar a contribuição da instituição de ensino superior para o processo evolutivo dos estudantes, mas nos anos de 2011 e 2014 o Inep convocou somente os concluintes. Por isso, nos concentramos somente nos dados referentes a essa última parcela de estudantes, uma vez que nossa intenção é analisar o perfil deles no decorrer de todas as edições do exame, na busca de traçar uma comparação entre os estudantes de um triênio para outro.

\section{0 que dizem os dados sobre $o$ perfil dos estudantes da carreira do magistério}

No decorrer de duas décadas recentes (19952015), a sociedade brasileira foi marcada por ações de dois governantes que se sucederam e implementaram políticas de expansão de acesso à educação superior. O primeiro, de vertente liberal, optou pela via da iniciativa privada, com incentivo ao financiamento estudantil. O segundo, com viés social, além dessa política, estimulou o aumento na quantidade de vagas nas instituições públicas existentes e criou novas universidades e institutos de ensino superior públicos, além de promover o custeio (bolsa) estudantil parcial ou integral. Essas ações contribuíram significativamente para o aumento no volume de faculdades e universidades, cursos, vagas e estudantes na educação superior, embora a grande maioria das matrículas (75\%) tenha sido realizada nas instituições privadas (RISTOFF, 2013, 2014, 2016). Assim, conquanto tenha ocorrido o fenômeno da "democratização do campus" (RISTOFF, 2016), com o aumento das matrículas próximo a 330\% no período de 1991-2011, a quan- 
tidade de estudantes nesse nível de escolaridade ainda é baixo, pois esse percentual representava no ano de 2011, segundo Lázaro (2016), pouco mais da metade $(17,3 \%)$ da meta de $30 \%$ da taxa líquida prevista no Plano Nacional de Educação (PNE) de 2001-2010 para a população com idade de 18 a 24 anos. Essa realidade se agrava se considerarmos que os estudantes que ingressaram no ensino superior estavam em instituições privadas e, portanto, expostos a inesperadas contingências financeiras, que afetam a continuidade dos estudos.

Não obstante o fato de o grande volume de matrículas estar alocado em instituições privadas, a implementação e o reforço de programas de inclusão universitária pelo governo federal, a partir da segunda metade dos anos 2000 - como o Programa de Apoio a Planos de Reestruturação e Expansão das Universidades Federais (Reuni), o Programa Universidade para Todos (Prouni), o Fundo de Financiamento Estudantil (Fies) e o Sistema de Seleção Unificado (Sisu) - contribuíram para aumentar o acesso à educação superior. A ampliação das matrículas ocorreu relativamente em todos os cursos (RISTOFF, 2016), porém foi nas licenciaturas a proporção mais elevada. Ristoff (2013), com base em dados do Censo da Educação Superior de
1991 a 2011, registra que a área da educação, que no ano de 1991 representava 8\% das matrículas, passou para $22 \%$ em 2000 , e se manteve em torno desse percentual nos anos posteriores.

Ao examinarmos os dados do Enade, observamos crescente quantidade de estudantes concluintes nos cursos de licenciatura. Conforme apresentamos na Tabela 1, na maioria das licenciaturas houve aumento médio de $75 \%$ do ano de 2005 para 2014. Alguns cursos apresentam percentuais mais elevados, como Educação Física, com aproximadamente 690\%, Pedagogia com 320\% e Química com $150 \%$. De um triênio para outro é possível constatar aumentos. Os únicos cursos que registram decréscimos são os de Geografia, do ano de 2008 para 2011, ao redor de 6\%; e Letras, do ano de 2011 para 2014, em torno de $2 \%$. A Tabela 1 também mostra a quantidade de estudantes nos cursos de bacharelado, que apresentamos a título de comparação com os correspondentes cursos de licenciaturas. Nesse caso, o percentual médio não ultrapassa $25 \%$ de estudantes em bacharelado, em relação aos de licenciatura, à exceção do curso de Educação Física, que, exclusivamente no ano de 2005, apresenta uma proporção inversa de aproximadamente $105 \%$.

Tabela 1 - Quantidade de estudantes que realizaram o Enade nos anos de 2005, 2008, 2011 e 2014.

\begin{tabular}{c|c|c|c|c|c|c|c|c}
\hline \multirow{2}{*}{ Curso } & \multicolumn{2}{|c|}{2005} & \multicolumn{2}{c|}{2008} & \multicolumn{2}{c|}{2011} & \multicolumn{2}{c}{2014} \\
\cline { 2 - 9 } & Licen. & Bach. & Licen. & Bach. & Licen. & Bach. & Licen. & Bach. \\
\hline Biologia & 8.940 & 1.993 & 10.102 & 4.903 & 14.145 & 5.931 & 15.645 & 6.063 \\
Ed. Física & 3.099 & 8.578 & 17.670 & ---- & 19.698 & ---- & 24.469 & ---- \\
Filosofia & 2.056 & ---- & 2.941 & --- & 3.070 & 860 & 3.559 & 1.145 \\
Física & 1.412 & 242 & 1.711 & 632 & 2.279 & 544 & 2.711 & 569 \\
Geografia & 6.075 & ---- & 8.234 & --- & 7.771 & 2.171 & 9.983 & 2.392 \\
História & 9.075 & ---- & 10.568 & --- & 11.509 & 1.107 & 17.199 & 1.459 \\
Letras & 21.337 & 1.533 & 22.752 & ---- & 26.659 & 972 & $26.081 *$ & 682 \\
Matemática & 8.697 & 546 & 10.066 & 281 & 11.303 & 236 & 13.422 & 387 \\
Pedagogia & 26.179 & ---- & 39.998 & --- & 87.759 & ---- & 111.863 & --- \\
Química & 2.117 & 531 & 3.292 & 1.285 & 3.967 & 2.925 & 5.202 & 3.239
\end{tabular}

Fonte: Elaborada pelo autor deste artigo com dados de relatórios síntese de área do Enade dos cursos de licenciatura (INSTITUTO NACIONAL DE ESTUDOS E PESQUISAS EDUCACIONAIS, 2005, 2008, 2011, 2014a).

Nota: Contempla os relatórios dos cursos de Letras: Português (Licenciatura e Bacharelado), Português/Inglês e Português/Espanhol. Os dois últimos somente Licenciatura. 
O expressivo aumento de estudantes nos cursos de licenciatura ocorreu por uma combinação de fatores que, em nosso entendimento, está relacionada ao que consideramos ser um "projeto nacional brasileiro" de democratizar o acesso à educação básica, com a universalização do ensino obrigatório, previsto na Constituição Federal e reforçado pela emenda constituinte 59, que estende essa condição para todos cidadãos na faixa etária de 4 a 17 anos. Essa empreitada, por sua vez, revelou a deficiência da nação em termos quantitativos e qualitativos de professores formados para essa missão. A respeito dessa carência, autores e entidades (BRASIL, 2007; GATTI, 2009; ORGANIZAÇÃO PARA A COOPERAÇÃO E DESENVOLVIMENTO ECONÔMICO, 2006) registraram o quadro com pior análise para a demanda no ensino médio, o que sugeria a urgente necessidade de intensificação de programas de incentivo à formação de professores.

No ano de 2006, uma comissão constituída por membros do Conselho Nacional de Educação para estudar formas de superar o déficit de professores para o ensino médio apontou, com base em dados do Inep, do Censo Escolar da Educação Básica e da educação superior, que havia “[...] uma necessidade de cerca de 235 mil professores para o Ensino Médio no país, particularmente nas disciplinas de Física, Química, Matemática e Biologia [...]" (RUIZ; RAMOS; HINGEL, 2007 p. 11). Gatti (2009) lembra que foi com base nos dados do Censo de Profissionais do Magistério do ano de 2003 que a extinta Secretaria de Educação a Distância (SEED), do Ministério da Educação (MEC), solicitou que as universidades públicas de todas as regiões do país ofertassem cursos de licenciatura em Pedagogia, Física, Química e Biologia e Matemática, para atender a um grande contingente de professores que atuavam sem ter a formação adequada.

O incentivo para o ingresso nos cursos de licenciaturas - tanto pelo investimento no aumento quantitativo de cursos e vagas (em cursos presencial e a distância) em instituições públicas (Reuni) e oferta de bolsa e financiamento estudantil (Prouni e Fies), como por meio de programas que pretendiam promover a valorização da carreira e melhoria da formação, como o Programa de Bolsa de Iniciação à Docência (Pibid) e o Programa Nacional de Formação de Professores da Educação
Básica (Parfor) - visou suprir a demanda de professores para a universalização da educação básica. Essa iniciativa do governo federal representou um avanço - mormente em razão da maior abertura ao ensino superior, sobretudo com a criação de novas instituições e campi universitários públicos -, mas estimulou também a propagação de cursos de licenciaturas em instituições privadas, visto que se trata de cursos que, na maioria, requerem menor investimento em instalações e equipamentos. Assim, e em razão da limitação de vagas nas instituições públicas de ensino superior, grande parte dos estudantes estão em instituições privadas, que não são contempladas com os programas citados e oferecem aos estudantes pouco auxílio financeiro (bolsas) visando incentivar estudos, iniciação científica ou atividade de extensão, que são práticas importantes no processo de formação.

Segundo dados do Censo da Educação Superior do ano de 2014, (INSTITUTO NACIONAL DE ESTUDOS PESQUISAS EDUCACIONAIS, 2014b) até aquele ano havia 2.368 instituições de ensino superior (IES), das quais 2.070 (78\%) de gestão privada, que abarcavam 1.850 faculdades, que são instituições isoladas, sem autonomia universitária. A título de comparação sobre o crescimento, no ano de 2000 existiam 1.004 IES privadas; no ano de 2003 já eram 1.652, um aumento maior que $60 \%$. Em relação ao número de vagas, em 2014, nos cursos de graduação, havia 8.081.369, com aproximadamente $90 \%$ em IES não públicas. As matrículas nos cursos de licenciatura naquele ano somavam 1.463 .548 , a maioria (59\%) em instituições de gestão privada. No ano de realização do Censo, o número de ingressantes nos cursos de licenciatura foi de 567.567, com 71\% em IES privadas. Com o intuito de comparação, no ano de 2003, as matrículas em todos os cursos eram de 3.887 .002 , com aproximadamente $28 \%$ desse total nos cursos de Administração e Direito. O estudo realizado pela Organização para a Cooperação e Desenvolvimento Econômico (OCDE) aponta os cursos de Negócios, Administração e Direito como os mais procurados em boa parte do mundo; cerca de $23 \%$ dos jovens que ingressam no ensino superior preferem essas áreas (ORGANISATION FOR ECONOMIC CO-OPERATION AND DEVELOPMENT, 2017a). 
Quadro 1 - Comparativo sobre o aumento de IES e vagas no ensino superior.

\begin{tabular}{|c|c|c|c|}
\hline Quantidade/Ano & $\mathbf{2 0 0 0}$ & $\mathbf{2 0 0 3}$ & $\mathbf{2 0 1 4}$ \\
\hline IES & 1.180 & 1.859 & 2.368 \\
\hline IES privada & 1004 & 1.652 & 2.070 \\
\hline Vagas nas IES & 1.216 .287 & 2.002 .733 & 8.081 .369 \\
\hline Vagas em IES privada & 970.655 & 1.721 .520 & 7.287 .421 \\
\hline Matrículas na licenciatura & 584.664 & 838.102 & 1.463 .548 \\
\hline $\begin{array}{c}\text { Matrículas na licenciatura } \\
\text { em IES privada }\end{array}$ & 319.348 & 455.744 & 862.657 \\
\hline
\end{tabular}

Fonte: Elaborada pelo autor deste artigo com dados do Censo da Educação Superior (INSTITUTO NACIONAL DE ESTUDOS PESQUISAS EDUCACIONAIS, 2000, 2003, 2014a).

No caso do Brasil, um fator que contribuiu para a expansão das matrículas foi a abertura de vagas em cursos ofertados na modalidade a distância. Segundo o Censo de 2014 (INSTITUTO NACIONAL DE ESTUDOS PESQUISAS EDUCACIONAIS, 2014a), 37\% do total de estudantes eram dessa categoria de educação, com $80 \%$ pertencentes à rede privada. Esses são dados, portanto, que mostram a abertura do ensino superior, porém com a concentração de matrículas em instituições privadas, embora o número de cursos de licenciatura no ano de 2014 fosse cerca de $20 \%$ maior em instituições públicas. Uma diferença que pode estar associada ao tipo de curso, como, por exemplo, licenciatura em Artes Visuais, Filosofia, Física, Música, Química, Teatro, Dança, que demandam mais recursos em infraestrutura e material e/ou têm baixa procura. Assim, os cursos como Letras, Matemática, Pedagogia, Biologia, Educação Física, História, Geografia, com maior quantidade de candidatos, como percebemos nos dados do Enade e do Censo da Educação Superior de 2014 (INSTITUTO NACIONAL DE ESTUDOS PESQUISAS EDUCACIONAIS, 2014a; 2014b), e que requerem menor exigência de investimento, são os que congregam mais estudantes e os mais ofertados por IES privadas.

$\mathrm{O}$ aumento na quantidade de estudantes no ensino superior, particularmente nas licenciaturas, caracterizado pelo processo de democratização do acesso, alterou o perfil da população do campus universitário (RISTOFF, 2013, 2016) em relação a idade, sexo, renda familiar, estado civil, cor. Considerando o caráter elitista e seletivo com que esse nível de educação foi edificado histo- ricamente, os estudantes ingressantes eram majoritariamente de cor branca. Dados do Instituto Brasileiro de Geografia e Estatística (IBGE) do ano de 2014 registram que a proporção de estudantes pretos ou pardos na faixa etária de 18 a 24 anos no ensino superior era de $45,5 \%$, enquanto em 2004 somente $16,7 \%$ de pessoas com essa definição de cor frequentavam esse nível. Um aumento significativo, porém, segundo o próprio IBGE, um percentual abaixo daquele alcançado por estudantes de cor branca 10 anos antes (INSTITUTO BRASILEIRO DE GEOGRAFIA E ESTATÍSTICA, 2015).

Em relação aos dados do Enade, (INSTITUTO NACIONAL DE ESTUDOS E PESQUISAS EDUCACIONAIS, 2005, 2008, 2011, 2014), relativos aos estudantes dos cursos de licenciatura, a faixa etária da maioria dos concluintes é de até 29 anos, todavia é possível verificar que houve aumento do grupo com mais de 30 anos (Tabela 2). O percentual é variado, desde $10 \%$ no curso de Geografia até $75 \%$ em Física; outros, como Letras, praticamente não apresentam variação. Esse aumento na quantidade de estudantes com idade mais elevada é representativo da ampliação de vagas e acesso ao ensino superior, uma vez que pode estar relacionado ao público de trabalhadores que não tiveram oportunidade de acesso a esse nível de escolarização imediatamente após concluir o ensino médio e/ou que não o concluiu na idade adequada em razão de atividade laboral. Os próprios dados do Enade (Gráfico 4) revelam que, na média, mais de $70 \%$ dos estudantes exercem atividade remunerada com carga horária de 20 horas ou mais. 
Tabela 2 - Percentual de estudantes em cada faixa etária, que realizou o Enade.

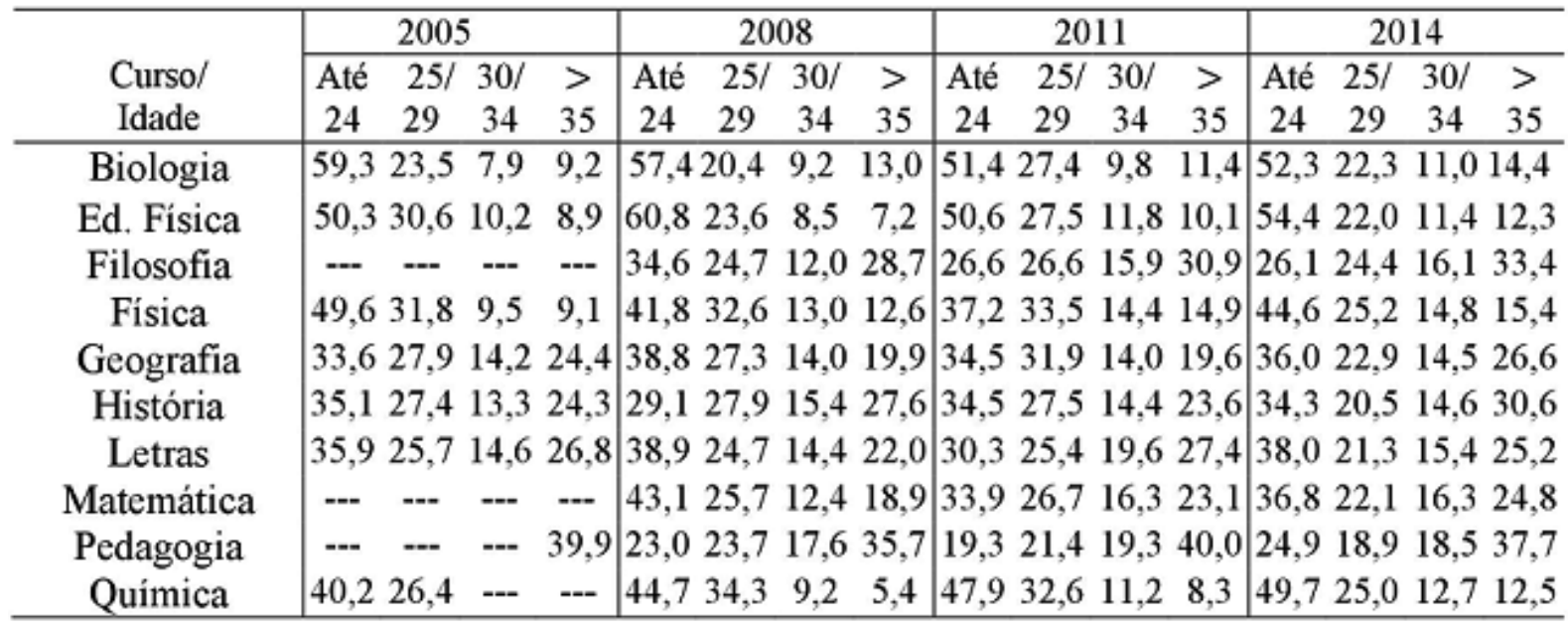

Fonte: Elaborada pelo autor deste artigo com dados dos relatórios síntese de área do Enade dos cursos de licenciatura (INSTITUTO NACIONAL DE ESTUDOS PESQUISAS EDUCACIONAIS, 2005, 2008, 2011; 2014).

Considerando a faixa de idade de 18 a 24 como ideal para cursar o ensino superior (INSTITUTO BRASILEIRO DE GEOGRAFIA E ESTATÍSTICA, 2015), é possível afirmar que a maioria dos estudantes está na faixa recomendada, exceto aqueles do curso de Pedagogia, cuja idade, na maior parte, tem início nos 30 anos, com predomínio para a faixa acima dos 35. Essa característica do curso de Pedagogia pode estar relacionada, entre outros aspectos, ao fato de parte dos estudantes ter realizado o ensino médio com a habilitação profissionalizante para o magistério dos anos iniciais da escolarização (Tabela 10); na sequência, esse grupo iniciou na carreira docente e somente depois de alguns anos ingressou no ensino superior. Também por se tratar de um curso muito procurado por um público que já possui uma licenciatura e deseja aprofundar estudos na área específica de educação e gestão escolar.

Ainda sobre a faixa etária dos estudantes, a OCDE registra que 26 anos é a média de idade com que as pessoas se formam na primeira graduação em vários países, ${ }^{1}$ embora haja variações, dependendo do percurso no ensino médio, da flexibilidade do sistema educacional para acomodar os estudantes no ensino superior, da relação entre trabalho e estudos dos indivíduos. Essa idade, segundo a entidade, se

1 Compreende os 35 países membros da OCDE, mais dois parceiros (Brasil e Rússia) que participam do Programa de Indicadores de Sistemas Educacionais da OCDE (INES), mais outros que participam do G20 (Argentina, China, Colômbia, Costa Rica, Índia, Indonésia, Lituânia, Arábia Saudita e África do Sul). baseia na média da idade de entrada dos estudantes no curso e o tempo para cursá-lo (ORGANISATION FOR ECONOMIC CO-OPERATION AND DEVELOPMENT, 2017a).

Em nosso estudo, como ilustrado na Tabela 2, os cursos em que a faixa etária é menos elevada são os de Biologia, Educação Física, Física e Química. Esses concentram a maior parte do público jovem, com idade até 24 anos, os dois primeiros, inclusive, com a maioria de concluintes nesse limite etário. Os cursos de Filosofia, Geografia, História e Letras, além de Pedagogia, são os que apresentam menor percentual de estudantes mais jovens. É preciso investigar essa relação entre faixa etária e opção pelo curso superior, porém conjecturamos que entre outros fatores (social, econômico, familiar etc.) há aqueles que dizem respeito à própria identidade do curso e sua representação social. Os cinco primeiros, por exemplo, embora estejam no contexto da formação do professor, são os que sugerem ser desenvolvidos em ambientes e ações que envolvem dinamismo, com atividades práticas e aulas laboratoriais/experimentais, além da perspectiva de que estão muito mais relacionados com a produção científica e tecnológica e aborda temas midiáticos, como meio ambiente, nanotecnologia, saúde, corpo, biodiversidade, exploração espacial etc., e que, portanto, podem exercer maior atração sobre os jovens egressos do ensino médio.

Outra característica dos estudantes dos cursos de licenciatura diz respeito ao sexo. Observamos 
que na maioria deles prevalece o público feminino, com exceção dos cursos de Educação Física, Filosofia e Física (Gráfico 1). No primeiro, há o predomínio masculino de $55 \%$, que se manteve ao longo das edições; no segundo o percentual é maior, porém com diminuição entre as edições do exame, da mesma forma como ocorreu com o terceiro. Os cursos com maior quantidade de estudantes do sexo feminino são Pedagogia ( $>90 \%$ ) e Letras $(>80 \%)$, seguidos por Biologia ( $>70 \%)$, História ( $>55 \%$ ), Química (55\%) e Geografia ( $>50 \%)$. Enquanto no curso de Química o percentual feminino aumentou no decorrer das edições, em Geografia e História ocorreu o inverso. Isso mostra que as mulheres estão se inserindo cada vez mais nas áreas tradicionalmente masculinas. Sobre isso, Guimarães (2001), ao apresentar dados que mostram aumento superior a $40 \%$ de ingresso de mulheres no mercado de trabalho entre os anos de 1980 e 1990 e somente de $3 \%$ de homens, registra que, se por um lado elas tenderam a ocupar postos historicamente femininos, por outro também se alocaram em redutos exclusivamente masculinos, como serviços de reparação. Segundo a autora, esse fenômeno ocorreu em razão da reestruturação empresarial na produção fabril, com a implementação da automação, que provocou a migração ocupacional e mobilidade na força de trabalho industrial. Não obstante o aumento das mulheres no mercado de trabalho, “[...] as segmentações, horizontais e verticais, entre empregos masculinos e femininos, perduram. As desigualdades de salário persistem, e as mulheres continuam a assumir o trabalho doméstico [...]" (KERGOAT, 2010, p. 94).

Gráfico 1 - Percentual de estudantes no Enade, segundo sexo.

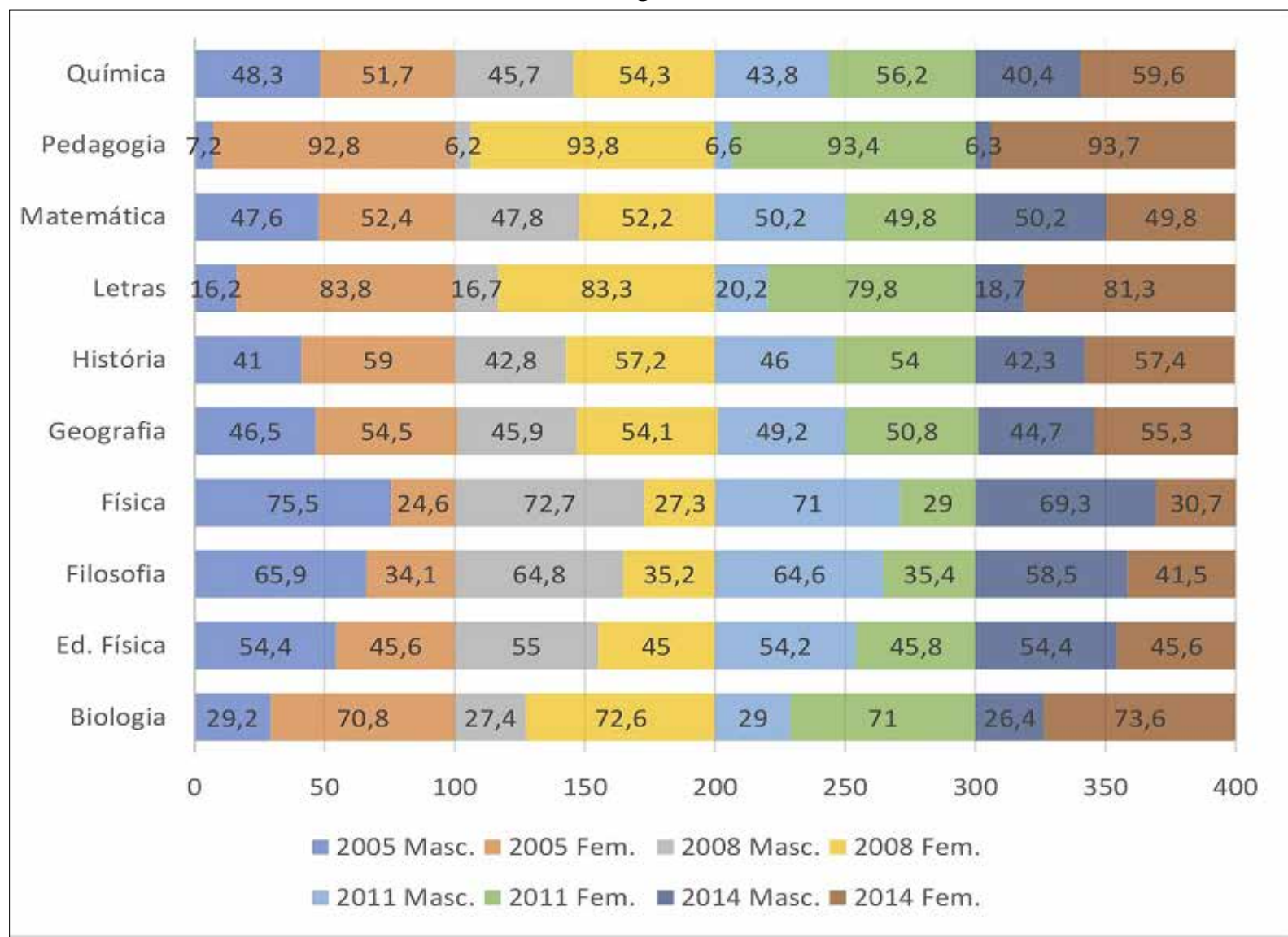

Fonte: Elaborado pelo autor deste artigo com dados de relatórios síntese de área do Enade dos cursos de licenciatura (INSTITUTO NACIONAL DE ESTUDOS E PESQUISAS EDUCACIONAIS, 2005, 2008, 2011, 2014).

Nota: Os percentuais dos cursos de Filosofia, Matemática, Pedagogia e Química do ano de 2005 não distinguem ingressantes e concluintes. 
A preponderância feminina nos cursos de licenciaturas poderia ser previsível, por se tratar de uma área de atuação profissional que, a partir do século XX, deixou de ser masculina em razão das mudanças nas relações sociais entre os sexos, tanto no mundo do trabalho, como na racionalização do capital (APPLE, 1988). Ao explicar as históricas transformações que ocorreram no mundo do trabalho nos EUA e Inglaterra, Apple (1988) registra que a racionalização econômica repercutiu diretamente nas relações de trabalho, causando uma expansão maior de posições com pouca autonomia ou controle, enquanto declinaram os empregos com altos níveis de autonomia, como no caso da educação, que foram preenchidos pelas mulheres. Esse autor argumenta ainda que não foi somente na área da educação que isso ocorreu, mas em várias atividades (escritórios, serviços de consumo pessoal, saúde e bem-estar), sobretudo em funções que exigiam baixa qualificação, tempo de trabalho parcial, pouca autonomia e grande controle externo.

Como uma referência dos anos de 1980 sobre a discussão relativa à organização sexual e temporal do trabalho e as consequências disso na vida dos trabalhadores, Murgatroyd (1982, p. 574) argumenta que o fator gênero exerce importância fundamental não só para fins de estabelecer os lugares das pessoas na divisão do trabalho, como também para situá-las na própria definição das ocupações, padronizando, dessa maneira, a divisão do trabalho. Ao falar dos processos históricos que definiram o trabalho de homem e o de mulher na sociedade, a autora afirma que:

[...] A divisão sexual do trabalho alterou-se juntamente com a divisão social do trabalho como um todo, da mesma forma que definições sociais quanto a adequação de homens e mulheres para executar diferentes tarefas mudou e as concepções culturais gerais de masculinidade e feminilidade foram modificadas [...] (MURGATROYD, 1982, p. 574-575, tradução nossa).

Embora seja marcante e fundamentalmente constituída a presença feminina no mercado de trabalho, tanto no setor de serviços quanto de produtos, como afirma Murgatroyd (1982), o trabalho da mulher é considerado inferior pelo simples fato de ser ela quem o realiza. Em cada um dos setores elas estão "[...] bem-representadas nas posições menos qualificadas, de menor status ou de remuneração inferior, enquanto os homens estão bem-representados nos empregos gerenciais e de alta qualificação [...]" (MURGATROYD, 1982, p, 582, tradução nossa). Na literatura atual, Hirata (2014, p. 8) considera que esse modelo de divisão do trabalho por sexo está relacionado a um fator que suplanta a ideia de complementaridade das atividades realizadas por homens e mulheres. Essa divisão é a concretização da relação de poder do homem sobre a mulher.

Sobre essa discussão, a respeito da divisão do trabalho na sociedade, a literatura aponta, segundo Hirata (2014), para um aspecto mais complexo que envolve não só a relação entre os sexos, mas também o fator racial. Hirata (2014, p. 62) apresenta uma discussão a respeito do surgimento do termo interseccionalidade, "[...] para designar a interdependência das relações de poder de raça, sexo e classe [...]" na sociedade. $\mathrm{O}$ foco maior dos estudos nesse assunto se concentra mais na relação entre sexo e raça. Para essa autora, as pesquisas interseccionais sobre trabalho se debruçam em perceber as desigualdades salariais, empregabilidade e tipo de ocupação considerando as relações entre homens brancos e negros e mulheres brancas e negras. Referindo-se a dados apresentados por Guimarães (2001), Hirata (2014, p. 63) afirma que “[...] considerando sexo e raça, os homens brancos possuem os salários mais altos; em seguida, os homens negros e as mulheres brancas; e, por último, as mulheres negras têm salários significativamente inferiores [...]". Os dados, segundo essa autora, também revelam que há quantidade maior de mulheres negras desempregadas e em trabalhos precários que mulheres brancas. No caso do Brasil, essas últimas têm percurso mais estável e prestigiado nas ocupações que as primeiras. Ainda sobre o enfoque relativo a cor/raça, Madalozzo e Artes (2017), ao traçar um perfil de trabalhadores brasileiros, tendo como parâmetro os dados da Pesquisa Nacional por Amostra de Domicílios (PNAD), do IBGE, do ano de 2013, mostram que a maioria daqueles que estão inseridos em ocupações imperiais (medicina, direito e engenharia) são homens e mulheres brancos, respectivamente $80 \%$ e $77 \%$. Nas profissões não imperiais, a maioria é de homens e mulheres não brancos, com $55 \%$ e $51 \%$ respectivamente. São 
dados que corroboram a divisão social do trabalho em razão de cor e sexo.

Segundo dados do IBGE, na série 2005-2015 (INSTITUTO BRASILEIRO DE GEOGRAFIA E ESTATÍSTICA, 2015), há uma trajetória de crescimento da mão de obra formal da mulher, porém com baixa contribuição para a previdência social, o que significa ausência de garantias (auxílio-doença e acidente de trabalho, salário-maternidade, aposentadoria). O documento também registra que embora as desigualdades entre homens e mulheres no mercado de trabalho tenham diminuído, os salários delas, geralmente, ainda são $24 \%$ menores que os deles, além dos tipos de ocupação, cargos de comando (chefia, gerencia, diretoria) e carga horária semanal. Essa informação reforça a visão de Kergoat (2009), de que há dois princípios organizadores da divisão do trabalho na sociedade, que é a separação das atividades entre os sexos: existem trabalhos para homens e trabalhos para mulheres; e a hierarquização: o trabalho realizado pelo homem vale mais que o trabalho da mulher. Assim, as relações sociais entre os sexos, constituídas historicamente e adaptadas em cada sociedade, definem a própria divisão sexual do trabalho. Nesse contexto, a destinação prioritária dos homens está ligada à "[...] esfera produtiva e das mulheres à esfera reprodutiva e, simultaneamente, a ocupação pelos homens das funções de forte valor social agregado (políticas, religiosas, militares etc.)" (KERGOAT, 2009, p. 67).

No âmbito educacional a relação se inverte; as mulheres não são somente maioria como profissionais (no caso da educação básica), elas também são maioria como estudantes. A presença do público feminino nos cursos de licenciatura é a reverberação do que ocorre, de modo geral, no ensino superior. Há um quantitativo $25 \%$ maior de mulheres nos cursos de graduação presenciais, registrado pelo Censo da Educação Superior em três anos consecutivos, e na educação a distância o percentual ultrapassa os 50\% (BRASIL, 2013). Das mais de 7,3 milhões de matrículas registradas no ano de 2013 nos cursos superiores, mais de $57 \%$ eram de mulheres. Não obstante, das oito grandes áreas do conhecimento: Ciências Sociais, Negócios e Direito; Serviços; Educação; Humanidades e Artes; Saúde e Bem-estar Social; Agricultura e
Veterinária; Ciências, Matemática e Computação; e Engenharia, Produção e Construção, há um predomínio dos homens nas três últimas, que estão relacionadas às Ciências da Terra, Ciências Exatas e Produção Industrial, uma vez que tais áreas dizem respeito à produtividade, atividade de domínio masculino na sociedade (KERGOAT, 2009). Nos cursos relacionados às matemáticas e engenharias, o público feminino é somente de $30 \%$ em relação aos homens.

Em âmbito internacional as mulheres também aparecem como maioria nos cursos universitários. Segundo registrado no relatório da OCDE, esse fenômeno ocorre em boa parte dos países. Com base em dados do ano de 2015, o documento mostra que em média o público feminino corresponde a $57 \%$ dos estudantes desse nível de educação. Revela também que as mulheres são mais propensas a completar o ensino superior do que os homens. Não obstante, segundo consta no relatório:

Embora a maioria dos egressos do ensino superior no ano de 2015 ser mulheres, os homens ainda têm melhores resultados no mercado de trabalho. Os ganhos dos homens com formação superior são mais elevados, em média, do que os das mulheres com formação superior e homens com formação superior tendem a ter taxas de emprego mais altas do que as mulheres com o mesmo nível de educação. (ORGANISATION FOR ECONOMIC COOPERATION AND DEVELOPMENT, 2017a, p. 67, tradução nossa).

Os dados do Censo da Educação Superior brasileiro (BRASIL, 2013), por sua vez, revelam que apesar de as mulheres serem perseverantes com sua escolarização, a escolha da carreira - apesar de elas terem alterado o cenário das profissões predominantemente masculinas, como as engenharias (LOMBARDI, 2006) - ainda está centrada em atividades em que o trabalho é mais fracionado, sofre maior controle e tem baixos salários, como registrado por Apple (1988), e, como tem sido apontado por outros autores, como, por exemplo, Guimarães (2001), Hirata (2014) e Kergoat (2009), reflete as relações de poder social configuradas nas diferenças de sexo, cor e condição econômica.

É preciso considerar que as escolhas profissionais, e consequentemente a opção pelo curso de graduação, são fortemente influenciadas pela 
família ou pelo contexto no qual as pessoas estão inseridas, o que, por sua vez, também estão relacionadas aos papéis sociais determinados aos sexos. Dessa maneira, algumas profissões parecem ao imaginário coletivo ser intrínsecas ao masculino ou ao feminino, como o magistério dos anos iniciais da escolarização, que associa a mulher ao cuidado de crianças (APPLE, 1988), e o homem à construção. Esses, entre outros aspectos, são indicadores da concentração feminina em determinados cursos, como mostram os dados do Censo e do Enade. Não obstante, é preciso considerar o constante aumento da presença da mulher nesse nível de ensino, que é, por um lado, fruto das suas próprias lutas e conquistas sociais e, por outro, como se refere Ristoff (2016), o processo de "democratização do campus".
Outro dado que reflete a ampliação da oportunidade de acesso ao ensino superior, e que também foi apontado por Ristoff (2016), diz respeito à cor dos estudantes. Em nossa análise sobre os dados do Enade, percebemos em cada edição do exame uma redução na quantidade da população de cor branca e aumento gradativo da parda e negra. ${ }^{2}$ Houve uma diminuição média de $32,8 \%$ de estudantes brancos do ano de 2005 para 2014 , com maiores proporções nos cursos de Biologia (50\%), Educação Física (43\%), Física (35\%) e Química (36\%). Inversamente, como é possível verificar no Gráfico 2, aumentou o número de pardos (33\%) e negros (49\%) matriculados, com os maiores percentuais também nos quatro cursos citados.

Gráfico 2 - Percentual de estudantes segundo cor no Enade 2005, 2008, 2011 e 2014.

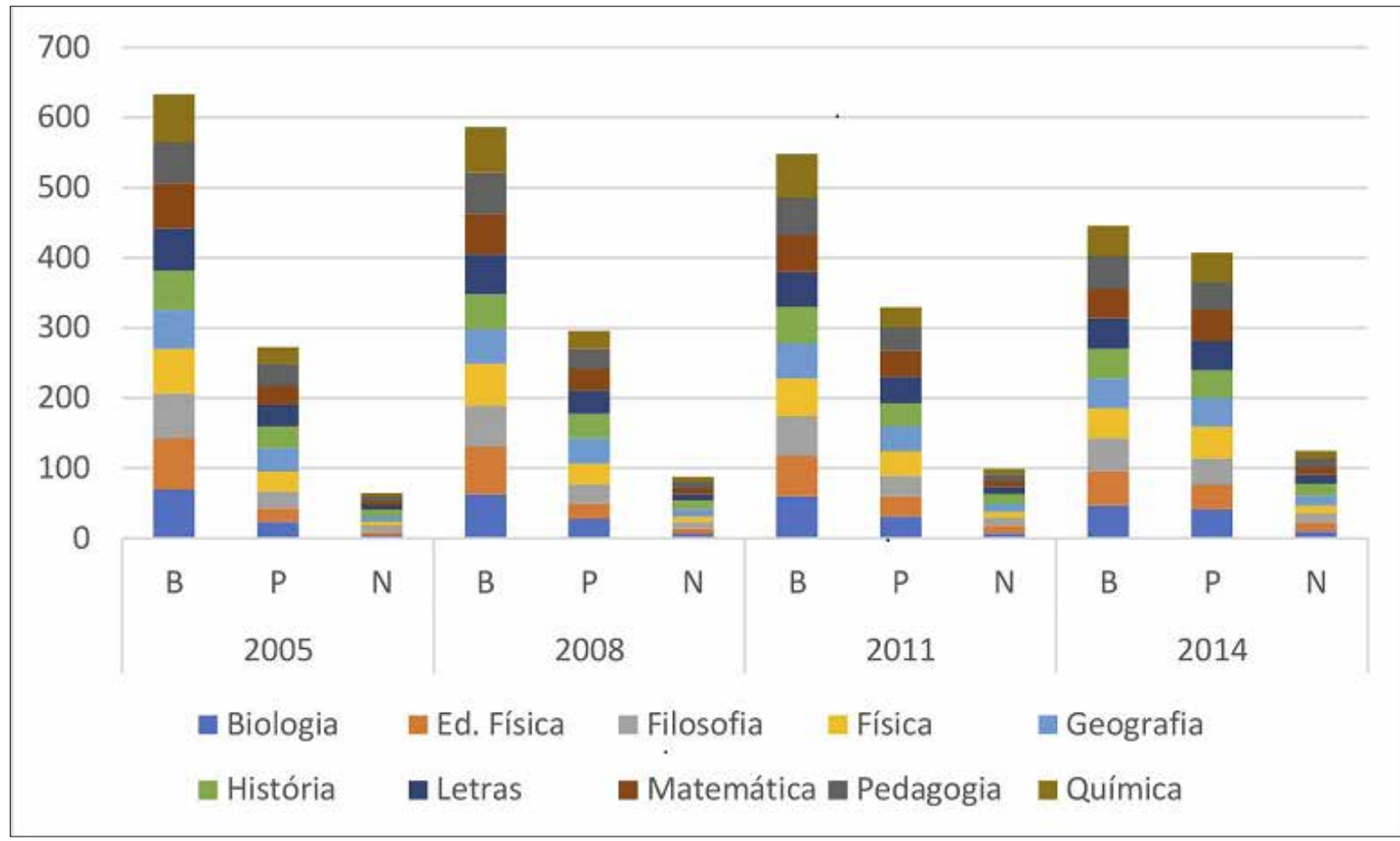

Fonte: Elaborado pelo autor deste artigo com dados de relatórios síntese de área do Enade dos cursos de licenciatura (INSTITUTO NACIONAL DE ESTUDOS E PESQUISAS EDUCACIONAIS, 2005, 2008, 2011, 2014).

Nota: $\mathrm{B}=$ branco(a); $\mathrm{P}=$ pardo(a); $\mathrm{N}=$ negro(a).

Essa ampliação de estudantes de cor parda e negra nos cursos de licenciatura é reflexo do que ocorreu no ensino superior de modo geral. As informações do IBGE também registram um aumento dessa presença nesse nível de ensino.
2 Embora o IBGE use a palavra preta para se referir à cor das pessoas, e não negra, e a literatura especializada parecer acompanhar essa denominação, o Inep, nos relatórios do Enade, utiliza o termo negro. Sem entrar no mérito dessa discussão, pois não é nosso propósito, para esse dado da nossa pesquisa utilizaremos o termo como apresentado nos relatórios que examinamos. 
Segundo o órgão, no que diz respeito à população na faixa etária de 18 a 24 anos, o percentual passou de 7,3\% no ano de 2005 para 12,8\% em 2015. Contudo, embora seja um crescimento significativo, permanecem as desigualdades entre cidadãos de cores/etnias diferentes, pois, como o próprio Instituto constata, essa taxa de ingresso de pardos e negros ainda está aquém dos 17,8\% alcançados por brancos no ano de 2005. Um dos fatores que contribuem para essa diferença é o atraso escolar, que atinge mais a população parda e negra que a branca: “[...] Em 2015, 53,2\% dos estudantes pretos ou pardos de 18 a 24 anos de idade cursavam níveis de ensino anteriores ao ensino superior, como o fundamental e o médio, enquanto apenas $29,1 \%$ dos estudantes brancos estavam nessa mesma situação" (INSTITUTO BRASILEIRO DE GEOGRAFIA E ESTATÍSTICA, 2015, p. 62).

Essa desvantagem escolar da população parda e negra em relação à branca é correlata à situação financeira da família. "À medida que cresce a renda domiciliar per capita, amplia-se a razão entre as taxas de frequência líquida na educação superior de pretos e pardos em relação à de brancos [...]" (INSTITUTO DE PESQUISA ECONÔMICA APLICADA, 2014, p. 23). Conquanto essa seja uma relação objetiva, não significa que ela, de fato, por si só, promova uma igualdade de acesso ao ensino superior, pois conforme registra a publicação do Instituto de Pesquisa Econômica Aplicada (2014), com base nos dados do IBGE de 2010, mesmo nas populações de brancos e pardos com renda familiar equalizada há uma diferença maior de aproximadamente $20 \%$ de brancos no ensino superior.

É fato que as políticas governamentais voltadas para a educação e outros programas sociais, visando a melhor distribuição de renda, aumento das vagas de emprego e democratização do acesso aos estudos universitários, implementados nos últimos 15 anos, contribuíram substancialmente para a ampliação da presença de negros e pardos no ensino superior. Todavia, é preciso considerar também as próprias lutas dos grupos étnicos, especificamente dos negros, que possibilitaram a eles alcançar reconhecimento social, participação política, valorização da cultura e ações afirmativas. Dessa maneira, nossa hipótese é que esse processo de marchas e conquistas, alimentado e alimentador das reivindicações mundiais por reconhecimento das minorias, dos grupos étnicos e respeito às diferenças entre as pessoas - com a adesão da indústria de produtos e serviços específicos e do poder midiático - estimulou as pessoas a assumirem sua cor/etnia e isso, portanto, se constitui em um dos aspectos que também contribuíram para revelar o aumento na quantidade de negros e pardos no ensino superior, uma vez que esses grupos assumiram, de fato, sua identidade.

A condição financeira dos estudantes dos cursos de licenciatura é outro dado que destacamos nos relatórios do Enade. Para analisar esse aspecto recorremos a três tipos de informações que o órgão responsável pelo exame coletou com os participantes: renda familiar (Tabela 3), sustentação financeira (Gráfico 3) e atividade laboral (Gráfico 4). Esses dados constituem o núcleo da condição econômica dessa parcela dos estudantes universitários brasileiros e caracterizam a escolha do curso e o próprio campo de atuação profissional.

No que se refere à renda familiar mensal dos estudantes, os relatórios dos anos de 2005 e 2008 (INSTITUTO NACIONAL DE ESTUDOS E PESQUISAS EDUCACIONAIS, 2005, 2008) apresentam cinco faixas de rendimento, que são: até 3 salários mínimos; mais de 3 até 10 salários mínimos; mais de 10 até 20 salários mínimos; mais de 20 até 30 salários mínimos; e mais de 30 salários mínimos. Para essa situação, elegemos para análise as três primeiras faixas, pois as demais apresentam percentuais inferiores a $2 \%$. Em relação aos anos de 2011 e 2014, os relatórios apresentam sete faixas: até 1,5 salário mínimo; acima de 1,5 até 3 salários mínimos; acima de 3 até 4,5 salários mínimos; acima de 4,5 até 6 salários mínimos; acima de 6 até 10 salários mínimos; acima de 10 até 30 salários mínimos; e maior que 30 salários mínimos. Não consideramos a última porque o percentual é menor que $1 \%$. Percebemos, então, que as escalas (faixas) de renda são diferentes entre as edições de coleta de dados. Assim, visando fazer uma análise comparativa entre os quatro anos, agrupamos as faixas dos dois últimos anos para adequá-las às faixas dos anos anteriores. Com isso, estabelecemos as seguintes faixas para os anos de 2011 e 2014: até 3; 4 a 10; e 11 a 30 (Tabela 3 ). 
Tabela 3 - Percentual de estudantes em cada faixa de renda familiar por ano de edição do Enade.

\begin{tabular}{|c|c|c|c|c|}
\hline CURSO/ANO & 2005 & 2008 & 2011 & 2014 \\
\hline \multirow{3}{*}{ Biologia } & Até $3=22,4$ & Até $3=47,2$ & Até $3=38,2$ & Até $3=61,8$ \\
\hline & 4 a $10=56,7$ & 4 a $10=41,5$ & 4 a $10=48,6$ & 4 a $10=35,2$ \\
\hline & 11 a $20=14,2$ & 11 a $20=8,4$ & 11 a $30=8,8$ & 11 até $30=2,8$ \\
\hline \multirow{3}{*}{ Ed. Física } & Até $3=23,7$ & Até $3=38,5$ & Até $3=36,8$ & Até $3=54,4$ \\
\hline & 4 a $10=52,3$ & 4 a $10=45,3$ & 4 a $10=51,9$ & 4 a $10=41,5$ \\
\hline & 11 a $20=16,2$ & 11 a $20=12,4$ & 11 a $30=8,3$ & 11 a $30=3,6$ \\
\hline \multirow{3}{*}{ Filosofia } & Até $3=26,4$ & Até $3=50,3$ & Até $3=40,1$ & Até 3 = 59,1 \\
\hline & 4 a $10=55,1$ & 4 a $10=36,6$ & 4 a $4,5=38,1$ & 4 a $10=35,6$ \\
\hline & 11 a $20=12,2$ & 11 a $20=8,6$ & 11 a $30=9,8$ & 11 a $30=4,4$ \\
\hline \multirow{3}{*}{ Física } & Até $3=25,5$ & Até $3=37,4$ & Até $3=36,6$ & Até $3=56,5$ \\
\hline & 4 a $10=52,3$ & 4 a $10=46,9$ & 4 a $10=48,8$ & 4 a $10=38,7$ \\
\hline & 11 a $20=16,3$ & 11 a $20=10,6$ & 11 a $30=10,3$ & 11 a $30=4,6$ \\
\hline \multirow{3}{*}{ Geografia } & Até $3=37,3$ & Até $3=54,9$ & Até $3=44,7$ & Até $3=62,5$ \\
\hline & 4 a $10=51,7$ & 4 a $10=37,8$ & 4 a $10=45,4$ & 4 a $4,5=34,9$ \\
\hline & 11 a $20=7,4$ & 11 a $20=5,6$ & 11 a $30=6,8$ & 11 a $30=2,4$ \\
\hline \multirow{3}{*}{ História } & Até $3=36,8$ & Até $3=54,8$ & Até $3=43,0$ & Até 3 $=60,7$ \\
\hline & 4 a $10=50,3$ & 4 a $10=34,9$ & 4 a $10=46,0$ & 4 a $10=35,9$ \\
\hline & 11 a $20=8,5$ & 11 a $20=6,1$ & 11 a $30=7,6$ & 11 a $30=3,1$ \\
\hline \multirow{3}{*}{ Letras } & Até $3=33,9$ & Até $3=56,9$ & Até $3=46,7$ & Até $3=66,1$ \\
\hline & 4 a $10=53,2$ & 4 a $10=36,8$ & 4 a $10=44,9$ & 4 a $10=31,3$ \\
\hline & 11 a $20=9,0$ & 11 a $20=4,9$ & 11 a $30=6,4$ & 11 a $30=2,4$ \\
\hline \multirow{3}{*}{ Matemática } & Até $3=22,2$ & Até $3=53,8$ & Até $3=44,2$ & Até $1,5=59,2$ \\
\hline & 4 a $10=65,1$ & 4 a $10=40,6$ & 4 a $10=48,0$ & 4 a $10=37,2$ \\
\hline & 11 a $20=9,0$ & 11 a $20=4,8$ & 11 a $30=5,7$ & 11 a $30=2,8$ \\
\hline \multirow{3}{*}{ Pedagogia } & Até $3=37,2$ & Até $3=60,2$ & Até $3=48,2$ & Até $3=64,8$ \\
\hline & 4 a $10=52,4$ & 4 a $10=33,3$ & 4 a $10=46,1$ & 4 a $10=33,3$ \\
\hline & 11 a $20=10,1$ & 11 a $20=3,8$ & 11 a $30=4,2$ & 11 até $30=1,7$ \\
\hline \multirow{3}{*}{ Química } & Até $3=22,0$ & Até $3=35,8$ & Até $3=32,8$ & Até $3=56,6$ \\
\hline & 4 a $10=59,5$ & 4 a $10=51,9$ & 4 a $10=53,8$ & 4 a $10=40,1$ \\
\hline & 11 a $20=14,5$ & 11 a $20=9,5$ & 11 a $30=10,0$ & 11 a $30=3,2$ \\
\hline
\end{tabular}

Fonte: Elaborada pelo autor deste artigo com dados de relatórios síntese de área do Enade dos cursos de licenciatura (INSTITUTO NACIONAL DE ESTUDOS E PESQUISAS EDUCACIONAIS, 2005, 2008, 2011, 2014).

Conforme é possível verificar na Tabela 3, houve aumento da população de estudantes nos cursos de licenciatura com renda familiar mais baixa na comparação entre o ano de 2005 e o de 2014 de realização do Enade. Percebe-se que na relação entre os dois primeiros anos de edição do exame (2005 e 2008) há grande diferença de público na faixa de até 3 salários mínimos. Nesse período a média de crescimento foi de $75 \%$, aproximadamente, com maior percentual no curso de Matemática (140\%) e menor em Física, Geografia e História (50\%), e nas outras faixas de renda há registro de redução da quantidade de estudantes. Na comparação entre 2008 e 2011, por sua vez, ocorreu uma diminuição de estudantes nessa faixa de renda de até 3 salários, e na comparação do ano de 2011 com 2014 voltou a aumentar na proporção de aproximadamente $60 \%$.
No ano de 2014 a maioria (60\%) dos estudantes concluintes da carreira do magistério que fizeram o Enade declarou ter renda familiar mensal de até 3 salários mínimos, e, conforme percebemos nos relatórios, mais de $40 \%$ dessa parcela estavam na faixa de até 1,5 salários. Se considerarmos o valor do salário mínimo na época de R\$ 724,00, assim como as despesas fixas mensais da população, como, por exemplo, energia elétrica, água, transporte, alimentação, e o próprio custo da educação superior privada, é muito difícil para essa população ter acesso a esse nível de escolarização se não for por meio de vagas em instituições públicas ou com programas governamentais de custeio. Sobretudo para as pessoas que estão inseridas no mercado de trabalho, que é maioria - como é possível notar nos percentuais dos Gráficos 3 e 4, que mostram respectivamente a dependência/independência 
financeira dos estudantes em relação à sua família e sua inserção em atividade laboral remunerada
- e que majoritariamente frequentam o curso no período noturno.

Gráfico 3 - Média do percentual de estudantes em relação a sua sustentação financeira.

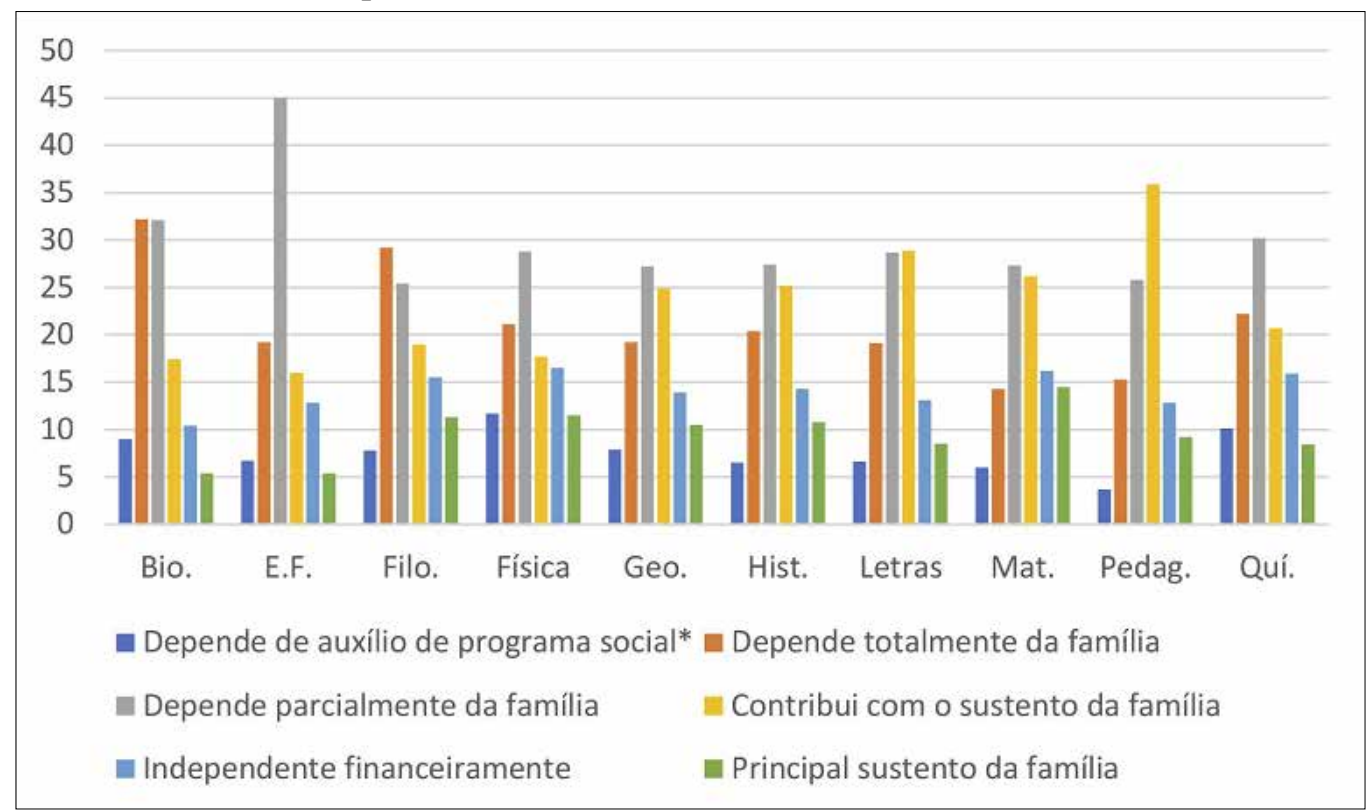

Fonte: Elaborado pelo autor deste artigo com dados de relatórios síntese de área do Enade dos cursos de licenciatura (INSTITUTO NACIONAL DE ESTUDOS E PESQUISAS EDUCACIONAIS, 2005, 2008, 2011, 2014). * Opção presente somente no relatório do ano de 2014.

Gráfico 4 - Percentual de estudantes em relação à atividade laboral.

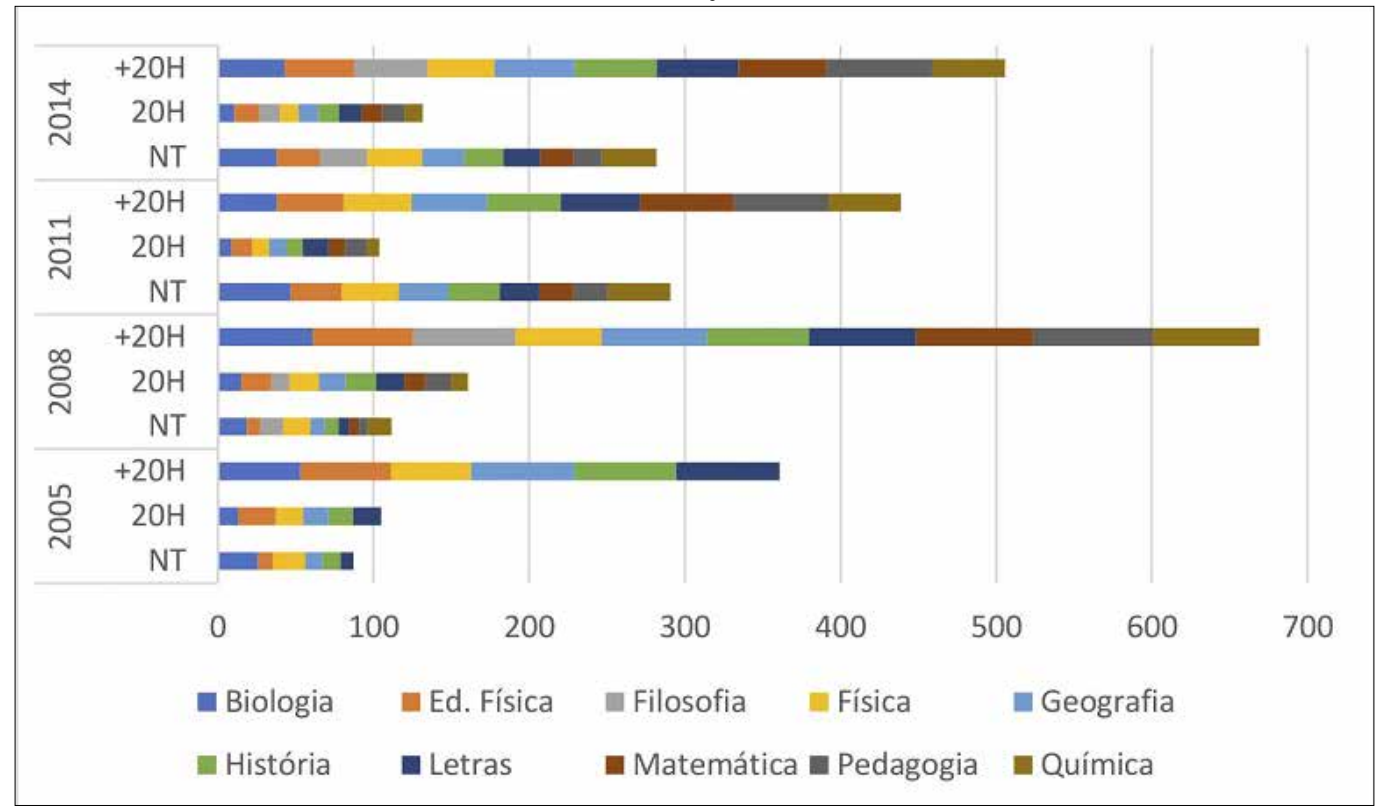

Fonte: Elaborado pelo autor deste artigo com dados de relatórios síntese de área do Enade dos cursos de licenciatura (INSTITUTO NACIONAL DE ESTUDOS E PESQUISAS EDUCACIONAIS, 2005, 2008, 2011, 2014). Nota: $\mathrm{NT}=$ não trabalha; $20 \mathrm{H}=$ trabalha até 20 horas semanais; $+20 \mathrm{H}=$ trabalha mais de 20 horas semanais. 
Com os percentuais do Gráfico 3, podemos perceber que aproximadamente $70 \%$ dos egressos das licenciaturas declararam não depender exclusivamente da família para custear seus gastos, o que sugere que eles exerciam atividade remunerada na época que responderam ao questionário. Essa afirmação é corroborada pelos dados presentes na Gráfico 4, que apresenta percentuais relativos àqueles que exerciam atividade no mercado de trabalho juntamente com os estudos. Nos anos de 2005 e 2008 os percentuais foram maiores, respectivamente $77 \%$ e $80 \%$; em 2011 houve uma redução e no ano de 2014 novo aumento.

Os cursos com maior quantidade de estudantes no mercado de trabalhos são Matemática e Peda- gogia, e aqueles com menor percentual são os de Biologia e Física.

Ao associarmos esses percentuais, de estudantes que trabalham com os dados sobre idade, presentes na Tabela 2, é possível inferir que os cursos de Pedagogia, Filosofia, Letras e Matemática são os que concentram estudantes que não ingressaram no ensino superior imediatamente após a conclusão do ensino médio, em razão da necessidade de contribuir com a renda familiar ou mesmo em razão de ser a única fonte de sustento dela. Sobretudo no caso daqueles que cursam Pedagogia e Matemática, pois são os que também possuem o maior percentual de casados. Esse conjunto de dados reforça, portanto, o perfil dos estudantes desses cursos, que têm idade mais elevada, estão no mercado de trabalho e são chefes de família.

Gráfico 5 - Percentual de estudantes em relação ao estado civil.

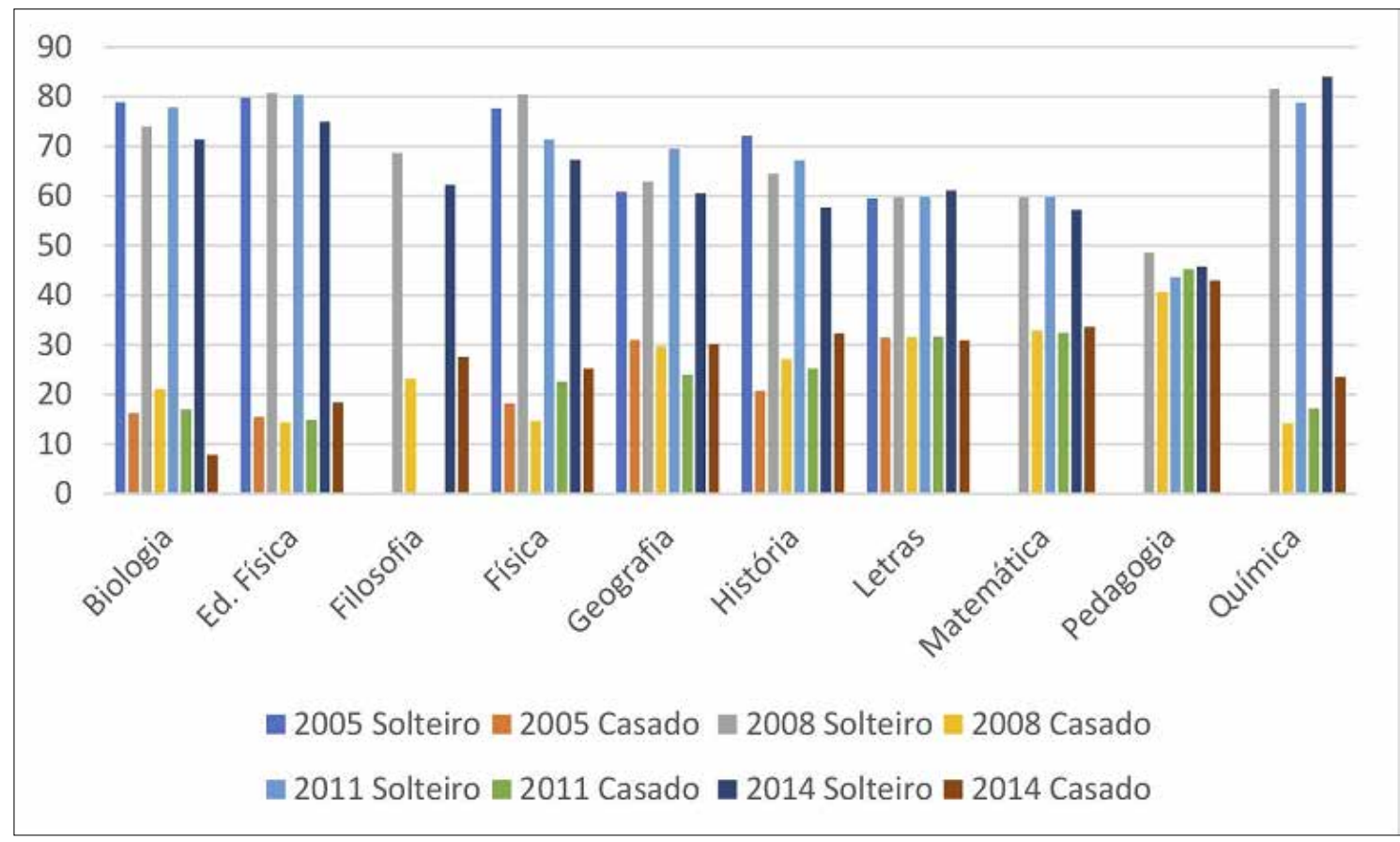

Fonte: Elaborado pelo autor deste artigo com dados de relatórios síntese de área do Enade dos cursos de licenciatura (INSTITUTO NACIONAL DE ESTUDOS E PESQUISAS EDUCACIONAIS, 2005, 2008, 2011, 2014). Nota: Os relatórios dos cursos de Matemática, Pedagogia e Química não registram dados sobre esse aspecto no ano de 2005, e os de Filosofia não registram em 2005 e 2011.

A relação com o trabalho e a responsabilidade com o sustento e cuidado com a família (total ou parcial) são características marcantes dos estudantes pobres em boa parte do mundo, tanto aqueles da educação básica como os do nível superior. O relatório do Programa Internacional de Avaliação de Estudantes (Pisa), ao divulgar dados relativos ao ano de 2015, sobre o "bem-estar" de estudantes da educação básica, na faixa etária de 15 a 16 anos, em mais de 30 países, registra que, no caso do Brasil, 
43,7\% desse público exercem trabalho remunerado antes ou depois de ir à escola. Pela primeira vez o Pisa perguntou aos estudantes de várias nações se trabalhavam de forma assalariada, ou em casa. Nos países membros da OCDE, 23\% dos estudantes responderam exercer atividade laboral fora de casa e $73 \%$ disseram executar tarefas domésticas não remuneradas, como, por exemplo, cuidar de pessoas. Em relação ao primeiro grupo, os meninos constituem a maioria; também é o grupo que apresenta maior percentual de estudantes com baixo desempenho em alguns componentes curriculares e sem expectativas com a educação escolar que recebem. Um em cada cinco desse grupo sente-se um "outsider" (estranho) na escola; 9\% chegam atrasados; $4 \%$ faltam com frequência; e $11 \%$ esperam concluir seu processo de educação formal ao terminar o ensino médio. São fatos que, segundo registrado no relatório, sugerem a falta de engajamento da escola com esses estudantes (ORGANISATION FOR ECONOMIC CO-OPERATION AND DEVELOPMENT, 2017b).

No que diz respeito ao estudante universitário, sua relação com o trabalho e o meio familiar aparece como categorias centrais na análise de estudos sobre sua identidade. Com essa perspectiva, o trabalho de Tosta (2017) apresenta uma reflexão sobre como alunos e alunas de uma universidade pública do Centro-Oeste brasileiro articulam o trabalho, a escolarização e a vida famíliar. Entre vários aspectos, essa autora caracteriza a condição socioeconômica da família dos estudantes que participaram da sua amostra de pesquisa, ressaltando que o jovem que está na universidade se destaca pela perspectiva de construir sua autonomia, o que requer independência financeira, principalmente para aqueles que não podem contar com as famílias para sustentar suas necessidades.

A preocupação em caracterizar esse público de estudantes não é recente. A pesquisa realizada por Foracchi no ano de 1964, com estudantes da Universidade de São Paulo (USP), com a pretenção de examinar o processo de transformação da sociedade brasileira por meio da ação de estudantes desse nível de educação, apresentou três categorias de análise: condição de classe das famílias dos universitários, forma de manutenção dessas famílias e dependência dos estudantes em relação aos pais. A autora percebeu, naquela época, que estava em transcurso uma mudança no perfil de classe social do público universitário. Considerando o contexto histórico e os limites da instituição onde realizou a coleta de dados, ela afirmou que os estratos superiores da sociedade não atingiam 30\% dos estudantes, em relação aos $71 \%$ pertencentes à classe média. Afirma ainda que naquela época o trabalho se configurava como fator revelador dessa mudança de perfil universitário, ao mesmo tempo que colocava à vista as barreiras socioeconômicas que se erigiam aos estudantes (FORACCHI, 1977).

Outro conceito apresentado por Foracchi (1977), para analisar a relação entre o estudante universitário e a família, é manutenção. “Quando o jovem é estudante, as relações de dependencia transparecem, no ambito da família, sob a forma de relações de manutenção, ou seja, formas cristalizadas de comportamento cuja análise representa importante ponto de partida para a investigação sociológica [...]" (FORACCHI, 1977, p. 17, grifo do autor). A dependência financeira da família submete o jovem estudante ao controle e normas familiares, o que, por sua vez, em alguns casos, pode gerar conflitos e descontentamento: "A dependencia econômica da família isenta o estudante de certas preocupações de manutenção mas restringe, em compensação, o limite da sua atuação [...]" (FORACCHI, 1977, p. 26). O trabalho, nesse caso, se configura como forma de não ser totalmente dependente dos pais, pois, mesmo que ainda esteja sob a autoridade familiar, não se submete totalmente aos posicionamentos políticos e ideológicos dos provedores. As outras formas da presença do trabalho na vida do estudante são em razão desse último ser parte constitutiva da renda familiar ou por ter que manter seu próprio sustento. O fato é que "[...] o trabalho representa, de modo parcial ou total [...] a garantia efetiva da possibilidade de manter-se como estudante, ao mesmo tempo que acena, para um sem-número de jovens, com a oportunidade de realizar um curso superior [...]" (FORACCHI, 1977, p. 124).

Com base nas contribuições de Foracchi (1977), Romanelli (1995) apresenta três categorias de compreenção a respeito do estudante universitário e sua manutenção financeira: "estudante em tempo integral", "estudante-trabalhador" e "trabalhador- 
-estudante". Em relação à primeira, Romanelli (1995) considera que há um projeto familiar em assegurar a escolarização do filho sem que ele cumpra outras obrigações. É um investimento que extrapola a educação do jovem, e fazendo isso a família está assegurando sua posição ou tentando ascender na hierarquia de classe social (FORACCHI, 1977). Esse tipo de estudante, embora sofra maior pressão e atrito familiar em razão da ausência de autonomia, possui formação de melhor qualidade, lhe assegurando, consequentemente, preparação para atuação profissional. Nessa situação também ocorre uma ambiguidade, pois ao mesmo tempo que isenta o estudante de preocupações com sua manutenção, restringe sua participação política e social, na medida em que limita suas opiniões e submete suas vontades ao domínio dos pais.

Quanto ao estudante-trabalhador, a dependência é parcial em relação aos pais, porém, mesmo quando a ajuda material é minima, permanece o vínculo familiar e, com isso, há controle e submissão às regras, embora para o estudante isso seja quase neutralizado. Pelo fato de trabalhar ele consegue emancipação parcial e a relação de dependência emerge como vínculo de retribuição. Também nesse caso ainda existe e é forte a intenção de investimento familiar na formação universitária do filho, como meio de ascensão de classe (FORACCHI, 1977). Em relação ao trabalho que desenvolve, o estudante-trabalhador o percebe como circunstancial, momentâneo, com o qual ele não tem preocupação ou perspectivas futuras, uma vez que não é objeto de qualificação universitária. $\mathrm{O}$ trabalho assume, dessa forma, um caráter emancipador provisório em razão da transitoriedade necessária.

O trabalhador-estudante, por sua vez, se refere à terceria categoria e diz respeito ao jovem trabalhador cuja família não possui condições de sustentá-lo de forma integral ou parcialmente nos estudos, ou mesmo que tenha a possibilidade de fazer isso, não considera prioridade esse tipo de investimento (ROMANELLI, 1995). Esse estudante, além de não dispor dos recursos da família, muitas vezes contribui com o sustento dela ou é seu provedor principal ou único. Para o autor, esse não é o estudante que trabalha, mas o trabalhador que estuda, por isso o trabalho é muito importante para ele, uma vez que é a fonte que supre suas necessidades. No caso desse estudante, a escolarização é um processo que acrescenta à sua atividade e identidade de trabalhador e que, dessa maneira, poderá contribuir para que ele alcance uma posição melhor no trabalho. Para esse jovem estudante a necessidade de trabalhar começa muito antes de ingressar no ensino superior, e é graças ao trabalho que ele pode fazer isso (FORACCHI, 1977).

Segundo Romanelli (1995), o estudante em tempo integral escolhe o curso universitário com base em vários fatores, entre eles, e com grande influência, a posição da família. Nos casos do estudante-trabalhador e do trabalhador-estudante há semelhanças entre si e diferenças em relação ao primeiro tipo. Para os dois últimos o investimento é vultuoso, pois não é, em muitos casos, só financeiro, é também de sobrevivência. Há necessidade de conciliar horários de estudo e trabalho, redução do tempo de repouso e lazer, deslocamentos e trabalhos rotineiros e desgastantes fisica e emocionalmente. Tudo isso para conquistar uma carreira profissional e, dessa maneira, ascender socialmente. O trabalho, portanto, “[...] é uma atividade imediata que possibilita o estudo, o qual, por sua vez, conduz à carreira [...]" (FORACCHI, 1977, p. 142).

No caso dos estudantes dos cursos de licenciatura que estamos examinando, cujo perfil é majoritariamente de trabalhador-estudante, conjecturamos que a opção deles pelo curso foi influenciada muito mais por fatores circunstanciais de acesso, custo, exigências de estudos, localidade, e, portanto, se constituem efetivamente como iniciativa contingencial do jovem, mais que uma consciência de vocação profissional ou projeto familiar. A tendência da família, quando investe na formação do filho, é interferir na escolha da profissão, de modo a direcioná-lo para uma situação que seja compatível com sua posição de classe social ou sirva para ascender a uma superior. No caso dos trabalhadores-estudantes essa intenção pode estar no horizonte, mas não há meios de se efetivar, uma vez que a sobrevivência deles está em primeiro plano. Dessa maneira, o plano para a vida não é estudar, mas trabalhar, pois essa segunda atividade se apresenta como fundamental para suprir a necessidade financeira: "[...] Aquilo que ele ganha não tem importância apenas para si próprio mas para 
a família [...]" (FORACCHI, 1977, p. 49). Nessa condição, é o trabalho, não o estudo, que acaba promovendo um vínculo do jovem com a família.

\section{Considerações finais}

Com a análise dos dados capturados com as quatro primeiras edições do Enade (2005, 2008, 2011 e 2014), em relação aos estudantes concluintes dos cursos de licencitura, percebemos que no transcurso dos anos houve expressivo aumento na quantidade de estudantes, com predomínio do sexo feminino, da cor branca e da faixa etária um pouco mais elevada em referência à idade de 18 a 24 para cursar o ensino superior (INSTITUTO BRASILEIRO DE GEOGRAFIA E ESTATÍSTICA, 2015). Isso ocorreu sobretudo nos cursos considerados da área de humanas (Filosofia, História, Geografia, Pedagogia, Letras). Também percebemos que é uma população majoritariamente trabalhadora e com baixa renda familiar.

No que diz respeito ao perfil dos estudantes dos cursos de licenciaturas, creio que não há grande diferencial a ser apontado em relação ao que a literatura tem registrado, à excessão do aumento pela procura desse tipo de curso e maior presença de pardos e negros, conforme classificação dos próprios relatórios examinados. Entretanto, esses dois aspectos estão relacionados ao que já discutimos sobre a expansão no quantitativo de vagas e de instituições de ensino superior, além do investimento em financiamento estudantil e, particularmente, no incentivo ao ingresso nos cursos de licenciaturas por meio de programas específicos, fruto de políticas governamentais de acesso à educação universitária que foram implementadas na última década.

O que consideramos ser relevante é o aumento na busca pela educação superior, que se caractariza como um fenômeno mundial (ORGANISATION FOR ECONOMIC CO-OPERATIONAND DEVELOPMENT, 2017a), fato que tem levado as classes menos favorecidas a aspirar esse nível educacional. As licenciaturas, historicamente, congregam a parcela de estudantes mais pobres em razão do status social e econômico que a carreira representa na sociedade. Por isso, não surpreende a falta de estudantes de camadas abastadas nesses cursos, assim como em outros que não têm reconhecimento social ou econômico e/ou estão relacionados com $\mathrm{o}$ atendimento à população de baixo poder aquisitivo, como, por exemplo, Enfermagem e Serviço Social. Famílias que podem investir na educação de seus filhos os encaminham para cursos de maior prestígio na sociedade. Contudo, segundo Ristoff (2016, p. 36):

[...] a cada edição do Enade decresce no campus brasileiro o percentual de estudantes das faixas de renda mais altas, o que significa dizer que cresce a representação de estudantes mais pobres. Esta tendência se aplica tanto aos cursos de alta, média e baixa demanda, demonstrando que as classes de renda mais baixa começam a se fazer presentes em maiores números em todas as áreas acadêmicas do campus $[\ldots]$.

Ainda segundo esse autor, embora esse quadro não altere o fato de que os cursos de alto prestígio permaneçam quase exclusivamente acessíveis somente à camada mais abastada da população, é preciso continuar investindo na democratização do acesso ao ensino superior na direção de aproximar o perfil socioeconômico dos estudantes universitários ao padrão de renda da maioria das famílias brasileiras. Sobre essa equalização, o relatório da OECD (2017a, p. 76, tradução nossa) registra que:

A educação está fortemente ligada aos ganhos, emprego, riqueza total e bem-estar das pessoas [...] Mas também pode perpetuar as desigualdades, se os níveis escolares não avançarem entre as gerações [...] Ao longo de suas vidas como trabalhadores, os adultos com menos formação escolar têm as maiores taxas de desemprego e inatividade, bem como os menores salários [...] Ter uma grande população de trabalhadores pouco qualificados pode, portanto, levar a um fardo social mais pesado [...] Garantir o acesso e o sucesso no ensino superior para todos é importante, como também tratar as desigualdades nas primeiras etapas da escolaridade. Nem todos alcançarão o ensino superior, mas todos devem, pelo menos, ter as mesmas oportunidades para atingir o nível de educação a que aspiram.

É de grande relevância o investimento público no acesso à educação superior, pois, como consta no relatório da $\mathrm{OECD}$, existe uma forte tendência daqueles que têm formação superior a investirem e incentivarem seus filhos a trilharem o mesmo caminho. Não obstante, a instituição universitária 
precisa ser menos canônica e ousar um pouco mais na formação profissional em função da realidade. Os cursos de licenciatura, por exemplo, precisam ser menos bacharelescos e mais propositivos em relação ao fazer pedagógico do professor da educação básica. As discussões que fundamentam e dão suporte para o entendimento sobre o fenômeno educacional devem se ancorar na dinâmica da escola. As dificuldades dos estudantes de licenciaturas, muitas delas em razão da baixa qualidade da escola básica, precisam ser eviden- ciadas, reconhecidas e trabalhadas. A universidade não pode ignorá-las, deixando que prossigam com elas ou, pior, excluindo os estudantes do processo, reprovando-os sucessivamente até que desistam. Não podemos ficar lamentando que as licenciaturas não atraiam jovens "talentosos" e que os professores não ensinem adequadamente bem os alunos nas escolas. Nossos estudantes nas licenciaturas são pobres e trabalhadores e é com eles que temos que trabalhar para fazer o melhor pela educação.

\section{REFERÊNCIAS}

APPLE, M. Ensino e trabalho feminino: uma análise comparativa da história e ideologia. Cadernos de Pesquisa, São Paulo, v. 64, p. 14-23, fev. 1988.

BRASIL. Presidência da República. Casa Civil. Lei no 9.131, de 24 de novembro de 1995. Altera dispositivos da Lei $\mathrm{n}^{\circ}$ 4.024, de 20 de dezembro de 1961, e dá outras providências. Brasília, DF, 1995. Disponível em: <http:// www.planalto.gov.br/ccivil_03/LEIS/L9131.htm>. Acesso em: 03 dez. 2018.

Presidência da República. Casa Civil. Lei no 9.394, de 20 de dezembro de 1996. Estabelece as diretrizes e bases da educação nacional. Brasília, DF, 1996. Disponível em: < http://www.planalto.gov.br/ccivil_03/LEIS/ L9394.htm>. Acesso em: 03 dez. 2018.

Presidência da República. Casa Civil. Lei no 10.861, de 14 de abril de 2004. Institui o Sistema Nacional de Avaliação da Educação Superior - SINAES e dá outras providências. Brasília, DF, 2004. Disponível em: <http:// www.planalto.gov.br/ccivil_03/_ato2004-2006/2004/lei/110.861.htm>. Acesso em: 03 dez. 2018.

BRITO, M. R. F. de. Enade 2005: perfil, desempenho e razão da opção dos estudantes pelas Licenciaturas. Avaliação, Campinas, SP, v. 12, n. 3, p. 401-443, set. 2007. Disponível em: <http://www.scielo.br/scielo.php?pi$\mathrm{d}=\mathrm{S} 1414-40772007000300003 \&$ script=sci_abstract\&tlng=pt $>$. Acesso em: 18 jul. 2017.

BRITTO, A. M.; WALTENBERG, F. D. É atrativo tornar-se professor do Ensino Médio no Brasil? Evidências com base em decomposições paramétricas e não paramétricas. Estudos Econômicos, São Paulo, v. 44, n. 1, p. 5-44, jan./mar. 2014. Disponível em: <https://www.revistas.usp.br/ee/article/view/42400>. Acesso em: 28 jul. 2017.

FORACCHI, M. M. O estudante e a transformação da sociedade brasileira. 2 ed. São Paulo: Cia Editora Nacional, 1977.

GATTI, B. A. (Org.). Professores do Brasil: impasses e desafios. Brasília, DF: Unesco, 2009.

Formação de professores no Brasil: características e problemas. Educação \& Sociedade, Campinas, SP, v. 31, n. 113, p. 1355-1379, out./dez. 2010.

GRIBOSKI, C. M. O Enade como indutor da qualidade da educação superior. Estudos em Avaliação Educacional, São Paulo, v. 23, n. 53, p. 178-195, set./dez. 2012. Disponível em: <http://www.fcc.org.br/pesquisa/publicacoes/ eae/arquivos/1763/1763.pdf>. Acesso em: 28 jul. 2017.

GUIMARÃES, N. A. Laboriosas mas redundantes: gênero e mobilidade no trabalho no Brasil dos 90. Revista Estudos Feministas, Florianópolis, v. 9, n. 1, p. 82-102, 2001. Disponível em: <file:///C:/Users/Paulo/Downloads/9675-28843-1-PB.pdf>. Acesso em: 30 jun. 2018.

HIRATA, H. Gênero, classe e raça. Interseccionalidade e consubstancialidade das relações sociais. Tempo Social, São Paulo, v. 26, n. 1, p. 61-73. 2014. Disponível em: <file://C:/Users/Paulo/Downloads/9675-28843-1-PB.pdf>. Acesso em: 30 jun. 2018.

INSTITUTO BRASILEIRO DE GEOGRAFIA E ESTATÍSTICA (IBGE). Síntese de indicadores sociais. Uma análise das condições de vida da população brasileira. Rio de Janeiro, 2015. (Estudos e Pesquisas. Informação 
Demográfica Socioeconômica, n. 35). Disponível em: <https://ndonline.com.br/files/images/2015/12/04-12-201502-58-43-pesquisa-ibge.pdf $>$. Acesso em: 20 ago. 2017.

INSTITUTO DE PESQUISA ECONÔMICA APLICADA (IPEA). Evolução do acesso de jovens à educação superior no Brasil. (1950 texto para discussão). Brasília, DF, 2014. Disponível em: <http://repositorio.ipea.gov. br/bitstream/11058/3021/1/TD_1950.pdf>. Acesso em: 20 ago. 2017.

INSTITUTO NACIONAL DE ESTUDOS E PESQUISAS EDUCACIONAIS (INEP). Censo da Educação Superior 2000. Brasília, DF, 2000. Disponível em: <http://download.inep.gov.br/download/censo/2000/Superior/ sinopse_superior-2000.pdf $>$. Acesso em: 15 maio 2017.

. Censo da Educação Superior 2003. Brasília, DF, 2003. Disponível em: <file://C:/Users/Paulo/Downloads/ Censo $\% 20 \mathrm{da} \% 20$ Educa\%C3\%A7\%C3\%A3o\%20Superior\%20sinopse $\% 20$ estat $\%$ C3\%ADstica\%20-\%202003\%20 (1).pdf $>$. Acesso em: 15 maio 2017.

Enade 2005. Relatório Síntese de Área. Brasília, DF: Ministério da Educação/Instituto Nacional de Estudos e Pesquisas Educacionais Anísio Teixeira - INEP, 2005. Disponível em: <http://portal.inep.gov.br/web/guest/ relatorios>. Acesso em: 18 set. 2016.

Enade 2008. Relatório Síntese de Área. Brasília, DF: Ministério da Educação/Instituto Nacional de Estudos e Pesquisas Educacionais Anísio Teixeira - INEP, 2008. Disponível em: <http://portal.inep.gov.br/web/guest/ relatorios>. Acesso em: 18 set. 2016.

Enade 2011. Relatório Síntese de Área. Brasília, DF: Ministério da Educação/Instituto Nacional de Estudos e Pesquisas Educacionais Anísio Teixeira - INEP, 2011. Disponível em: <http://portal.inep.gov.br/web/guest/ relatorios>. Acesso em: 18 set. 2016.

Enade 2014. Relatório Síntese de Área. Brasília: Ministério da Educação/Instituto Nacional de Estudos e Pesquisas Educacionais Anísio Teixeira - INEP, 2014a. Disponível em: <http://portal.inep.gov.br/web/guest/ relatorios>. Acesso em: 18 set. 2016.

Censo da Educação Superior 2014. Brasília, DF, 2014b. Disponível em: <http://download.inep.gov.br/ educacao_superior/censo_superior/documentos/2015/notas_sobre_o_censo_da_educacao_superior_2014.pdf $>$. Acesso em: 15 maio 2017.

KERGOAT, D. Divisão sexual do trabalho e relações sociais de sexo. In: HIRATA, H. Et al. (Org.). Dicionário crítico do feminismo. São Paulo: Unesp, 2009. p. 67-75.

Dinâmica e consubstancialidade das relações sociais. Revista Novos Estudos - CEBRAP, São Paulo, n. 86, p. 93-103, 2010. Disponível em: <http://www.scielo.br/pdf/nec/n86/n86a05.pdf > . Acesso em: 30 jun. 2018.

LÁZARO, A. Editorial. In: RISTOFF, D. Democratização do campus. Impacto dos programas de inclusão sobre o perfil da graduação. Rio de Janeiro: Flacso Brasil/GEA, 2016. (Cadernos do GEA, n. 9).

LOMBARDI, Maria R. Engenheiras brasileiras: inserção e limites de gênero no campo profissional. Cadernos de Pesquisa, v. 36, n. 127, p. 173-202, jan./abr. 2006.

LOUZANO, P. Et al. Quem quer ser professor? Atratividade, seleção e formação docente no Brasil. Estudos em Avaliação Educacional, São Paulo, v. 21, n. 47, p. 543-568, set./dez. 2010. Disponível em: <http://www.fcc.org. br/pesquisa/publicacoes/eae/arquivos/1608/1608.pdf>. Acesso em: 12 ago. 2017.

MADALOZZO, R.; ARTES, R. Escolhas profissionais e impactos no diferencial salarial entre homens e mulheres. Cadernos de Pesquisa, São Paulo, v. 47, n. 163, p. 202-221, jan./mar. 2017. Disponível em: <http://www.scielo. br/pdf/cp/v47n163/1980-5314-cp-47-163-00202.pdf>. Acesso em: 12 ago. 2017.

MURGATROYD, Linda C. Gender and occupational stratification. The Sociological Review, v. 30, n. 4. p. 574602, nov. 1982.

ORGANIZAÇÃO PARA A COOPERAÇÃO E DESENVOLVIMENTO ECONÔMICO (OCDE). Professores são importantes: atraindo, desenvolvendo e retendo professores eficazes. Relatório de pesquisa. São Paulo: Moderna, 2006.

ORGANISATION FOR ECONOMIC CO-OPERATION AND DEVELOPMENT (OECD). Education at a Glance 2017-OECD indicators. Paris, 2017a. Disponível em: $<$ http://www.oecd-ilibrary.org/education/education-at-a-glance-2017_eag-2017-en>. Acesso em: ago. 2017. 
PISA 2015 Results (Volume III). Students’ well-being. Paris, 2017b. Disponível em: <http://www.oecd. $\overline{\mathrm{org} / \mathrm{pisa}} /$ publications/pisa-2015-results-volume-iii-9789264273856-en.htm>. Acesso em: ago. 2017.

RISTOFF, D. Vinte e um anos de educação superior. Expansão e democratização. Rio de Janeiro: Flacso Brasil/ GEA, 2013. (Cadernos do GEA, n. 3). Disponível em: <http://flacso.org.br/?publication=caderno-gea-n3-vinte-e-um-anos-de-educacao-superior-expansao-democratizacao>. Acesso em: 10 jul. 2017.

O novo perfil do campus brasileiro: uma análise do perfil socioeconômico do estudante de graduação. Avaliação, Campinas, SP, v. 19, n. 3, p. 723-747, nov. 2014. Disponível em: <http://www.scielo.br/scielo.php?pi$\mathrm{d}=\mathrm{S} 1414-40772014000300010 \&$ script=sci_abstract\&tlng=pt $>$. Acesso em: 13 jul. 2017.

Democratização do campus. Impacto dos programas de inclusão sobre o perfil da graduação. Rio de Janeiro: Flacso Brasil/GEA, 2016. (Cadernos do GEA, n. 9). Disponível em: <http://flacso.org.br/?publication=caderno-gea-n9-democratizacao-do-campus-impacto-dos-programas-de-inclusao-sobre-o-perfil-da-graduacao $>$. Acesso em: 10 jul. 2017.

ROMANELLI, G. O significado da educação superior para duas gerações de famílias de camadas médias. Revista Brasileira de Estudos Pedagógicos, Brasília, DF, v. 76, n. 184, p. 445-476, set./dez. 1995. Disponível em: <http:// rbep.inep.gov.br/index.php/rbep/article/view/1100/1074>. Acesso em: 30 jul. 2017.

RUIZ, A. I; RAMOS, M. N.; HINGEL, M. Escassez de professores no Ensino Médio: propostas estruturais e emergenciais. Relatório produzido pela Comissão Especial instituída para estudar medidas que visem a superar o déficit docente no Ensino Médio (CNE/CEB). Brasília, DF: MEC/CNE/CEB, 2007. Disponível em: <http://portal. mec.gov.br/cne/arquivos/pdf/escassez1.pdf>. Acesso em: 03 dez. 2018.

SILVA, M. C. R. da; VENDRAMINI, C. M. M.; LOPES, F. L. Diferenças entre gênero e perfil socioeconômico no exame nacional de desempenho do estudante. Avaliação, Campinas, SP, v. 15, n. 3, p. 185-202, nov. 2010. Disponível em: $<$ http://www.scielo.br/scielo.php?pid=S1414-40772010000300010\&script=sci_abstract\&tlng=pt $>$. Acesso em: 28 jul. 2017.

TOSTA, T. L. D. A participação de estudantes universitários no trabalho produtivo e reprodutivo. Cadernos de Pesquisa, São Paulo, v. 47, n. 165, p. 896-910, jul./set. 2017. Disponível em: <http://www.scielo.br/pdf/cp/ v47n165/1980-5314-cp-47-165-00896.pdf>. Acesso em: 30 out. 2017.

WAINER J.; MELGUIZO, T. Políticas de inclusão no ensino superior: avaliação do desempenho dos alunos baseado no Enade de 2012 a 2014. Educação e Pesquisa, São Paulo, v. 44, p. 1-15, jan. 2017. Disponível em: <http:// www.scielo.br/scielo.php?script=sci_abstract\&pid=S1517-97022017005001103\&lng=pt\&nrm=iso $>$. Acesso em: 20 jul. 2017.

Recebido em: 09/11/2018

Aprovado em: 11/11/2018 